\title{
Occupation and its association with Carpal Tunnel syndrome- A Review
}

\author{
Jagga, V., Lehri, A. \& Verma, S.K. \\ Research Scholar, Dept of Sports Science, Punjabi University, Patiala-147001, Punjab \\ Assistant Professor, Dept of Sports Science, Punjabi University, Patiala-147001, Punjab \\ Professor, Dept of Sports Science, Punjabi University, Patiala-147001, Punjab
}

\begin{abstract}
Carpal tunnel syndrome (CTS) is a common problem with estimated annual incidence rate of 0.5-5.1 per 1000. Its incidence in the workplace has reached epidemic proportions, comprising 40.8 percent of all upper extremity repetitive motion. Certain occupational activities also carry an increased risk of CTS. A number of etiological factors have been suggested to be potentially etiologic for CTS. These include repetitive prolonged hand intensive activities, forceful exertions awkward or static posture, vibration, temperature extremes and localized mechanical stress. Referred literature was collected up to June 2011 mentioning carpal tunnel syndrome and occupation and textbook of orthopaedic physiotherapy third edition by Robert Donateli and Wooden. Most of the articles dealt with prevalence, diagnosis, and description of carpal tunnel syndrome. Various articles from the collected data were based on occupational studies. The references were further supplemented by systematic search on Pubmed, Google and Pedro with keywords occupation, incidence, and prevalence with carpal tunnel syndrome. Several specific occupational studies that had been reviewed in these were found to deal with meat, cut metal workers, supermarket workers, meat industry workers, slaughter house, assembly line workers, meat and fish process, manufacturing, construction and agriculture workers, musicians, ski manufacturing, frozen food factory employees, repetitive industrial work groups, poultry processing workers, heavy wrist movements and heavy manual workers, packaging industry workers, footwear factory, grocery store workers etc. These studies were included in the review. In summary, a useful body of research now supports and extends previous conclusions that certain occupations involving wrist activities materially increases the risk of carpal tunnel syndrome. Prolonged exposure to highly repetitive flexion and extension of the wrist should be avoided.
\end{abstract}

KEY WORDS: Carpal Tunnel Syndrome, Occupation, Repetitive Flexion, Repetitive Extension

\section{Introduction}

Carpal tunnel syndrome (CTS) is defined as a complex of symptoms arising from compression of the median nerve at the carpal tunnel. Symptoms of median nerve compression include pain, numbness, or tingling on the anterior surface of the index, middle, or radial half of the ring finger. It is often associated with weakness of hand grip or nocturnal symptoms including hand or arm pain and numbness. Provocative physical examination techniques such as Tinel's sign, Phalen's sign, and a two point discrimination test have been used to support the diagnosis of this condition. Median nerve entrapment is the pathological process that causes symptoms of CTS.

Carpal tunnel syndrome is a common problem with estimated annual incidence rate of $0.5-5.1$ per 1000 . Its incidence in the workplace has reached epidemic proportions, comprising 40.8 percent of all upper extremity repetitive motion disorders as reported by the Bureau of Labor Statistics in 1994. It was first discovered in 1947 that CTS was related to occupation, when Brian et al (1947) reported approximately 6 cases of work - 
related CTS in repetitive work. Occupational CTS is a major cause of lost work days and workers compensation costs. It is characterized by sensory and less commonly motor symptoms and signs in the peripheral distribution of median nerve. The known causes of CTS include Trauma, Diabetes, Rheumatoid Arthritis, Acromegaly, Hypothyroidism and Pregnancy. The association of CTS with work related risk factors is a recurring theme of causation among workers, ergonomists, lawyers and physicians. The majority of the literature that tries to establish this as a casual association fails to meet the appropriate standards of epidemiologic validity.

Certain occupational activities also carry an increased risk of CTS. A study by Yves Roouelaurs et al (2008) provides high quality information on occupational association of CTS. High prevalence were observed in manufacturing (42-93\% for both sexes), Construction (66\% for men) and personal service industries $(66 \%$ for women) and in the trade and commerce sectors (49\% for women). A systemic review done by Keith et al. in 2007 identified 38 primary reports that provided information that regular and prolonged use of hand vibrating tools increases risk of CTS more than 2 folds and found substantial evidence for similar or even higher risks from prolonged and highly repetitious flexion and extension of wrist specially when associated with forceful grip. In an another study done by Joon Youn Kim et al (2004) it was concluded that frequency of CTS occurrence is more in high risk industry jobs. A number of etiological factors have been suggested to be potentially etiologic for CTS. These include repetitive prolonged hand intensive activities, forceful exertions awkward or static posture, vibration, temperature extremes and localized mechanical stress.

\section{Material \& Methods}

Referred literature was collected up to June 2011 mentioning carpal tunnel syndrome and occupation and textbook of orthopaedic physiotherapy third edition by Robert Donateli and Wooden. Most of the articles dealt with prevalence, diagnosis, and description of carpal tunnel syndrome. Various articles from our collected data were based on occupational studies. The references were further supplemented by systematic search on Pubmed, Google and Pedro with keywords occupation, incidence, and prevalence with carpal tunnel syndrome. Several specific occupational studies that had been reviewed in these were found to deal with meat, cut metal workers, supermarket workers, meat industry workers, slaughter house, assembly line workers, meat and fish process, manufacturing, construction and agriculture workers, musicians, ski manufacturing, frozen food factory employees, repetitive industrial work groups, poultry processing workers, heavy wrist movements and heavy manual workers, packaging industry workers, footwear factory, grocery store workers etc. These studies were included in the review. The search was further refined by restricting attention to English language publications and to papers that included specified epidemiological terms. Titles, articles and abstracts were studied duplicates and obviously irrelevant references were eliminated by the researchers. 


\section{Results}

In the research of literature reviewed up to June 2011, 60 papers were identified. The evidence on carpal tunnel syndrome and different occupations are considered under the following subheadings:

1. Vibration exposed workers

2. Assembly line workers

3. Food processing, Slaughter house \& Frozen food factory workers

4. Grocery store workers

5. Manufacturing unit or Industrial workers

6. Textile workers

7. Computer users.

Vibration exposed workers: Strong evidence is shown in many researches that decreasing the acceleration level of a handheld vibrating tool has a positive relationship with the prevalence of HAVS (Hand arm vibration syndrome). In a study of Finnish forestry workers using chain saws, Koskimies et al (1992) found that the prevalence of HAVS symptoms declined from a peak of $40 \%$ to $5 \%$ after the introduction of light-weight, lowvibration chain saws with reduced acceleration from 14 to $2 \mathrm{~m} / \mathrm{s}^{2}$. Likewise, a study of similar workers in Japan by Futatsuka and Uneno $(1985,1986)$ found that the prevalence of vascular symptoms among chain saw operators who began their jobs before the introduction of various engineering and administrative controls peaked at 63\%. (Vibration acceleration levels for chain saws used during this period ranged from 111 to 304 $\mathrm{m} / \mathrm{s}^{2}$ ). In contrast, the peak prevalence for chain saw operators who began working after the introduction of anti-vibration chain saws (acceleration level: 10-33 $\mathrm{m} / \mathrm{s}^{2}$ ) and exposure duration limits (2 hrs/day) was only $2 \%$. According to Gemne et al (1993), the absorption of vibration energy by the hand is influenced by the vibration intensity, as well as by frequency, transmission direction, grip and feed forces, hand-arm postures, and anthropometric factors. Several studies reviewed found relationships between prevalence of HAVS and duration of vibration exposed work [Bovenzi, 1994; Bovenzi et al, 1995; Letz et al, 1992; Nilsson et al, 1989]. One cross-sectional study reported no association with duration of exposure (Musson et al, 1989). However Sandén et al (2010) observed no differences in distal latencies between subjects exposed to hand-arm vibration and unexposed subjects, neither in the sensory conduction latencies of the median nerve, nor in the motor conduction latencies of the median and ulnar nerves. Seven subjects $(9 \%)$ in the exposed group and three subjects $(12 \%)$ in the unexposed group had both pathological sensory nerve conduction at the wrist and symptoms suggestive of carpal tunnel syndrome.

Assembly line workers: With regard to assembly work, a greater than doubling of risk was reported by Abbas et al (2001) who studied personal and work related risk factors associated with carpal tunnel syndrome in electronic assembly and clerical workers in Egypt. They observed that electronics assembly workers were more likely to report CTS (odds ratio $\{\mathrm{OR}\}=11.41)$ whose jobs involved a precision (pinch) grip and frequent repetition. Barnhart et al (1991) found that in ski assembly workers employed for an average of 5.1 years in jobs that entailed 'repeated and/or sustained' flexion, extension or ulnar or radial 
deviation of the wrist, Carpal tunnel syndrome was observed in either or both hands in $15.4 \%$ of those workers with repetitive jobs, but only in $3.1 \%$ of those workers with non-repetitive jobs. The conclusion was drawn that carpal tunnel syndrome is associated with jobs requiring frequent and sustained hand work (OR 4.0). Bystrom et al (1995) \& Michael Spallek et al (2010) revealed that in automobile assembly workers OR is 2.9, but with wide confidence limits. Leclerc et al (1998) did study on workers assembling small electrical appliances, motor vehicles and ski accessories (OR 4.5). Cannon and co-workers (1981) did a case-control study of 30 subjects in an aircraft engine assembly plant who were identified as having the carpal tunnel syndrome. Three variables were found to be predictive of the development of the carpal tunnel syndrome: using vibrating hand tools.

Food processing, Slaughter house \& Frozen food factory workers: In the foodprocessing and food-packing industries, excess risks were reported by the following people: (i) Schottland et al (1991) in poultry workers (OR 2.9); (ii) Frost et al (1998) in slaughterhouse workers stated $5.1 \%$ of the non-deboning slaughterhouse workers [prevalence ratio (PR) $3.23,95 \%$ confidence interval $(95 \%$ CI) 1.3-7.99] and $7.8 \%$ of the deboning slaughterhouse workers (PR 4.91, 95\% CI 2.03-11.81) had CTS \& conclude daily high-velocity and high-force manual work is a risk factor for CTS; (OR 3.3-5.5); (iii) Kim et al (2004) in their study on meat and fish processing plant workers, observed that fifty-one $(73.9 \%)$ workers in the experimental group had findings compatible to the NIOSH definition of
Work-Related CTS. The prevalence of CTS in a meat and fish processing plant was much higher. Therefore Chiang et al (1990) was of the view that the jobs in the frozen-food factory should be considered as high-risk jobs. They studied three groups of workers. Group I (with subjects involved in little exposure to cold and low repetitive movements of the wrist) served as the internal standard. In group II (subjects having no local exposure to cold, but a high degree of repetitiveness) and group III (had those subjects who had a combination of local exposure to cold and a high degree of repetitiveness). They observed that the risk of CTS for group II + III was 14.39 times higher than that of group I. Group III still had a higher risk of CTS than group II. Repetitiveness as well as hands' local exposure to cold was found to be contributing factors leading to CTS (OR 11.7).

Osorio et al. in 1994 studied 56 supermarket workers. Exposure to repetitive and forceful wrist motions was rated as high, moderate, or low, following observation of job tasks. The CTS case definition was based on symptoms and nerve conduction studies. CTS-like symptoms occurred more often (OR 8.3, 95\% CI 2.6-26.4) among workers in the high exposure group compared to the low exposed group. The odds of meeting the symptom and NCS-based CTS case definition among the high exposure group were 6.7 (95\% CI 0.8-52.9), compared to the low exposure group. Baron et al. in 1991 studied CTS in 124 grocery store checkers and 157 other grocery store workers who were not checkers. The CTS case definition required symptoms that met pre-determined criteria on a standardized questionnaire and physical 
examinations. The OR for CTS among checkers was 3.7 (95\% CI 0.7-16.7), in a model that included age, hobbies, second jobs, systemic disease, and obesity. Participation rates at the work sites were higher among the exposed group (checkers: $85 \%$ participation, noncheckers: $55 \%$ participation). After telephone interviews in which $85 \%$ of the non-checkers completed questionnaires, investigators reported that the proportion of non-checkers meeting the case definition did not increase. Morgenstern et al. in 1991 mailed questionnaires to 1,345 union grocery checkers and a general population group. Exposure was based on self-reported time working as a checker. Symptoms of CTS were significantly associated with age and the use of diuretics, and non-significantly associated with average hours worked per week, and years worked as a checker. A positive CTS outcome was based on the presence of all four symptoms: pain in the hands or wrist, nocturnal pain, tingling in the hands or fingers, or numbness. The estimated attributable fraction of CTS symptoms to working as a checker was about 60\%, using both a general population comparison group and a low exposed checker group. The limitations of this study are: (i) the use of an overly sensitive health outcome measure, for example, $32 \%$ of the surveyed population reported numbness; and (ii) the use of self-reported exposure. The survey with the questionnaire reported that $12 \%$ to $62.5 \%$ of supermarket checkers were somewhat affected by CTS. The NCS found that $20 \%$ of workers using vibratory tools including chain saw, $5.5 \%$ of instrument players and $6.4 \%$ of dentists had CTS.

Roquelaure et al in 2002 in shoe factory stated that on the basis of 72 prevalence data, three types of work situation were detected to be at high risk of MSDs: cutting, sewing, and assembly preparation. The three types of work situations identified on the basis of incidence data (sewing preparation, mechanized assembling, and finishing) were different from those identified by prevalence data. At least one recognised risk factor for MSDs was identified for all groups of work situations. The ergonomic risk could be considered as serious for the four types of work situation having the highest ergonomic scores (sewing, assembly preparation, pasting, and cutting). Silverstein et al. in 1987 studied 652 workers in 39 jobs from 7 different plants (electronics, appliance, apparel, and bearing manufacturing; metal casting, and an iron foundry). Investigators divided jobs into high or low repetitiveness categories, based on analysis of videotaped job tasks of 3 representative workers in each job. High repetitiveness was defined as cycle time less than 30 seconds or at least $50 \%$ of the work cycle spent performing the same fundamental movements. Jobs were also divided into high or low force categories based on EMGs of representative workers' forearm flexor muscles while they performed their usual tasks. EMG measurements were averaged within each work group to characterize the force requirements of the job. High force was defined as a mean adjusted force $>6 \mathrm{~kg}$. Jobs were then classified into 4 groups: low force/low repetitiveness, high force/low repetitiveness, low force/high repetitiveness, and high force/high repetitiveness. Fourteen cases $(2.1 \%$ prevalence) of CTS were diagnosed based on standardized physical examinations and structured interviews. Hagberg. $M$ et al, in 1992 studied 15 cross-sectional 
studies involving 32 occupational or exposure groups and six case-referent studies. The prevalence of CTS in the different occupational groups varied between 0.6 and $61 \%$. The highest prevalence was noted for grinders, butchers, grocery store workers, frozen food factory workers, platers, and workers with high-force, high-repetitive manual movements \& concluded that exposure to physical work load factors, such as repetitive and forceful gripping, is probably a major risk factor for CTS in several types of worker populations. However, Gedizlioglu. M et al, in 2008 in steel industry has found no cases of CTS in heavy manual workers, but sub clinical involvement of peripheral nerves. The key point of the study is that in this group of manual workers, manual work was not a risk factor for the development of clinical CTS;

McCormack et al. in 1990 studied 1,579 textile production workers and compared them to 468 other non-office workers, a comparison group that included machine maintenance workers, transportation workers, cleaners, and sweepers. The textile production workers were divided into four broad job categories based on similarity of upper extremity exertions. formal exposure assessment was conducted. Health assessment included a questionnaire and screening physical examination followed by a diagnostic physical examination. CTS was diagnosed using predetermined clinical criteria. The severity of cases was also reported as mild, moderate, or severe. The overall prevalence for CTS was $1.1 \%$, with $0.7 \%$ in boarding, $1.2 \%$ in sewing, $0.9 \%$ in knitting, $0.5 \%$ in packaging/folding, and $1.3 \%$ in the comparison group. None of the differences were statistically significant. A statistical model that also included age, gender, race, and years of employment showed that CTS occurred more often among women in this study $(p<0.05)$. Interpretation of these data, especially with a low prevalence disorder like CTS, is difficult since gender varied with job (94\% of boarding workers were female, compared to $56 \%$ in the comparison group), and the comparison group (machine maintenance workers, transportation workers, cleaners and sweepers) may have also been exposed to upper extremity exertions. Interactions among potential confounders were not addressed, but they are suspected because of significant associations between race and three MSDs.

Andersen et al in 2003 in computer workers conclude that self-reported prevalence of tingling/numbness in the right hand at baseline was $10.9 \%$. The interview confirmed that prevalence of tingling/ numbness in the median nerve was $4.8 \%$, of which about one third, corresponding to a prevalence of $1.4 \%$, experienced symptoms at night. Onset of new symptoms in the 1-year follow-up was $5.5 \%$. In the cross-sectional comparisons and in the follow-up analyses, there was an association between use of a mouse device for more than $20 \mathrm{~h} / \mathrm{wk}$ and risk of possible CTS but no statistically significant association with keyboard use. The occurrence of possible CTS in the right hand was low. The study emphasizes that computer use does not pose a severe occupational hazard for developing symptoms of CTS. A survey was done by J. Clarke Stevens et al in 2001 of employees who were identified as 
frequent computer users. Although 29.6\% of the employees reported hand paraesthesia, only 27 employees $(10.5 \%)$ met clinical criteria for carpal tunnel syndrome, and in $9(3.5 \%)$ the syndrome was confirmed by nerve conduction studies. Affected and unaffected employees had similar occupations, years using a computer, and time using the computer during the day. The frequency of carpal tunnel syndrome in computer users is similar to that in the general population.

In most of the studies diagnosis of CTS was based on a combination of signs, symptoms and electrophysiological findings, but the exact criteria applied varied between investigations. For example, some required the demonstration of abnormal conduction in the median nerve as a condition for inclusion, whereas others accepted positive physical signs as an alternative. A few studies took a reported or documented medical diagnosis of CTS as their case definition, and others defined cases on the basis only of symptoms.

Repeated flexion and extension of the wrist (defined in various ways) more than doubled the risk of physicianconfirmed CTS was found in many studies, three studies point to wrist flexion or extension for at least half the working day as carrying a particularly high risk. In the study by (i) Silverstein et al. in 1987 in a well-known and careful survey that spanned several industries and included videotaped job analysis, reported associations both with repetitive and with forceful hand-wrist work. For repetitive work (hand-wrist flexion and extension), defined by a cycle time of , $30 \mathrm{~s}$ or $.50 \%$ of cycle time involved in performing the same fundamental activities, the OR was
2.7 (95\% CI 0.3-28) in low-force jobs (hand force, $1 \mathrm{~kg}$ ) and 15.5 (95\% CI 1.7142) in high-force jobs (hand force $.4 \mathrm{~kg}$ ). (ii) de Krom et al. in 1990 found that risks were elevated 5- to 8-fold when the selfreported time spent in activities with the wrist flexed or extended was $20 \mathrm{~h} /$ week, while in the study by Nordstrom et al. the OR for CTS was more than doubled for those estimating that they bent/twisted their wrists for $3.5 \mathrm{~h} /$ day versus $0 \mathrm{~h} /$ day. A study by (iii) Wieslander et al. in 1989 suggested that risk may double after 1 year in a job involving 'repetitive wrist movement', while another by Tanaka et al. found that risks were increased nearly 6-fold in workers bending/twisting the hand or wrist 'many times per hour'. Two other studies, by Leclerc et al. in 1998 \& 2001 and Roquelaure et al. in 1997, found associations with assembly work that involved a short elemental cycle time (10 s per repetition, RRs 1.9 and 8.8).

\section{Discussion}

The carpal tunnel syndrome is felt to be induced or aggravated by any process that compresses the median nerve as it passes through the narrow confined space of the carpal tunnel. Repetitive flexion and extension of the wrist and grasping motions of the hand are thought to repeatedly compress the median nerve between the tendons and carpal bones, leading to injury to the median nerve. These motions also place a person at risk for the development of tendonitis and the accompanying swelling of the synovial sheath within the carpal tunnel with secondary compression of the median nerve.

Reasonable evidence was found that repetitive work increases the risk of carpal tunnel syndrome. There were three different studies reporting association 1) 
high repetition and high force in the hands 2) vibration exposure 3) occupation. A study by Roquelaure et al (2008) and Joon youn kim et al (2004) supported this evidence. Another review done by Keith et al (2006) also supported that repetitive prolonged hand intensive activities, forceful exertions awkward or static posture, vibration and localized mechanical stress are associated with carpal tunnel syndrome.

There was surprising consistency of observed effects across the different studies. Occupational tasks or job titles associated with vibration exposure repetitive hand movements and forceful grips were reported in most of the studies as risk factor for carpal tunnel syndrome. Vibration exposure and packaging is probably an indicator of exposure to forceful repetitive gripping. In the study Leclerc et al studied that carpal tunnel syndrome is present in one or both hands in $11.8 \%$ workers in repetitive work and frequency was high in packaging (16.2\%), In an another study Kim et al in 2004 found that the prevalence of CTS in a meat and fish processing plant that involve repetitive working was much higher. Keith et al in 2006 identified 38 primary reports that provided higher quality information that regular and prolonged use of hand held vibratory tools increase the risk of carpal tunnel syndrome more than 2 fold and found substantial evidence for similar or even higher risks from prolonged and highly repetitious flexion and extension of the wrist especially when allied with a forceful grip.

One inconsistency was noted Viikarijuntura in 1999 reported only 1\% prevalence with repetitive work involving job title cutter. Juntunen et al in 1983 also questioned the association between vibration exposure and carpal tunnel syndrome claiming that patients with neuropathic diatheses, who are at greater risk for CTS tend to be selected into group of patients with vibration syndrome. IF so the frequency of carpal tunnel syndrome would be higher among exposed workers because of earlier diagnosis or detection in this group. However this detection bias was not present in the studies in which the same diagnostic procedures were used for the study.

In summary, a useful body of research now supports and extends previous conclusions that certain occupation having wrist activities materially increases the risk of carpal tunnel syndrome. Prolonged exposure to highly repetitive flexion and extension of the wrist should be avoided.

\section{References}

Abbas, M.F., Faris, R.H., Harber, P.I. 2001. Worksite and personal factors associated with carpal tunnel syndrome in an Egyptian electronics assembly factory. Int. J. Occup. Environ. Health, 7: 31-36.

Andersen, J.H. 2003. Computer Use and Carpal Tunnel Syndrome A 1-Year Follow-up Study. JAMA, 289(22): 2963-2969

Armstrong, T.J., Chaffin, D.B. 1979. Carpal tunnel syndrome and selected personal attributes. Occup. Med. 21: 481-6.

Aroori, S., Roy, A. Spence, J. 2008. Carpal tunnel syndrome. Ulster. Med. J. 77(1): 6-17.

Barnhart, S., Demers, P.A., Miller, M., Longstreth, W.T.J., Rosenstock, L. 1991. Carpal tunnel syndrome among ski manufacturing workers. Scand. J. Work Environ. Health. 17: 46-52.

Baron, S., Milliron, M., Habes, D., Fidler, A. 1991. Hazard evaluation and technical assistance report: Shoprite Supermarkets, New JerseyNew York. Cincinnati, OH: U.S. Department of Health and Human Services, Public Health Service, Centers for Disease Control, National 
Institute for Occupational Safety and Health, NIOSH Report No. HHE 88-344, 2092.

Bonfiglioli, R., Mattioli, S., Spagnolo, M.R., Violante, F.S. 2006. Course of symptoms and median nerve conduction values in workers performing repetitive jobs at risk for carpal tunnel syndrome. Occup. Med. (Lond). 56(2): $115-21$

Bovenzi, M. 1994. Hand-arm vibration syndrome and dose-response relation for vibrationinduced white finger among quarry drillers and stone-carvers. Occup. Env. Med. 51(9): 603-611.

Bovenzi, M,. Franzinelli, A., Mancini, R., Cannava, M.G., Maiorano, M., Ceccarelli, F. 1995. Dose-response relation for vascular disorders induced by vibration in the fingers of forestry workers. Occup. Env. Med. 52: 722-730.

Brian, R.W., Wright, A.D. and Wilkinson, M., 1947. Spontaneous compression of both median nerves in the carpal tunnel syndrome. Lancet 1: $277-282$

Butcthal, F. and Rosenfalck, A. 1966. Evoked action potentials and conduction velocity in human sensory nerves. Brain. Res, 3: 1.

Bystrom, S., Hall, C., Welander, T., Kilbom, A. 1995. Clinical disorders and pressure-pain threshold of the forearm and hand among automobile assembly line workers. J. Hand. Surg. (Br) 20:782-790.

Campbell, W.W, Ward, L.C and Swift, T.R. 1980. Nerve conduction velocity varies inversely with height. Muscle Nerve. 3: 436.

Cannon, L.J., Bernacki, E.J., Walter, S.D. 1981. Personal and occupational factors associated with carpal tunnel syndrome. J. Occup. Med. 23: $255-258$

Chiang, H.C., Chen, S.S., Yu, H.S., Ko, Y.C. 1990. The occurrence of carpal tunnel syndrome in frozen food factory employees. Gaoxiong $\mathrm{Yi}$. Хие. Ке. Хие. Za. Zhi. 6: 73-80.

Croft, P. 1993. Soft tissue rheumatism. Epidemiology of the Rheumatic Diseases (Oxford University Press In: Silman AJ and Hochberg MC (Eds.), Oxford. 399-408.

de Krom, M.C., Kester, A.D., Knipschild PG, Spaans F. 1990. Risk factors for carpal tunnel syndrome. Am. J. Epidem. 132: 1102-1110.

Frost, P., Andersen, J.H., Nielsen, V.K. 1998. Occurrence of carpal tunnel syndrome among slaughterhouse workers. Scand. J. Work. Environ. Health. 24: 285-292.

Futatsuka, M., Uneno, T. 1985. Vibration exposure and vibration induced white finger due to chain saw operation. J. Occup. Med. 27: 257264.

Futatsuka, M., Uneno, T. 1986. A followup study of vibrationinduced white finger due to chain saw operation. Scand. J. Work. Environ. Health. 12(4): 304-306

Gamstorp, I. 1963. Normal conduction velocity of ulnar, median and peroneal nerves in infancy, childhood and adolsence. Acta. Paed. 68: 146.

Gedizlioglu, M. 2008. Carpal tunnel syndrome in the Turkish steel industry. Occup. Med. 58: 212-214

Gemne, G., Lundström, R., Hansson, J. 1993. Disorders induced by work with hand-held vibrating tools: a review of current knowledge for criteria documentation. Arbete. Och. Halsa. 6: 1-83.

Hagberg, M., Morgenstern, H., Kelsh, M. 1992. Impact of occupations and job tasks on the prevalence of carpal tunnel syndrome. Scand. J. Work. Env. Health, 18: 337-345.

Halar, M., DeLisa, J.A., Soine, T.L. 1983. Nerve conduction in upper extremities: Skin temperature correlation. Arch. Phys. Med. Rehab. 64: 142.

Juntunen, J., Matikainen, E., Seppalainen, A.M, Laine A. 1983. Peripheral neuropathy and vibration syndrome. Int. Arch. Occup. Environ. Health. 52: 17-24.

Kim, J.Y., Kim, J.I., Son, J.E., Yun, S.K. 2004. Prevalence of carpal tunnel syndrome in meat and fish processing plants. J. Occup. Health. 46: 230-234.

Koskimies, K., Pyykko, I., Starck, J., Inaba, R. 1992. Vibration syndrome among Finnish forest workers between 1972 and 1990. Int. Arch. Occup. Environ. Health. 64(4): 251-6

Kuorinka, I. and Forcier, L. 1995. Work-Related Musculoskeletal Disorders (WMSDs): A Reference Book for Prevention (Taylor and Francis, London).

Leclerc, A., Franchi, P., Cristofari, M.F. 1998. Carpal tunnel syndrome and work organisation in repetitive work: a cross sectional study in France. Study Group on Repetitive Work. Occup, Env. Med. 55: 180187.

Leclerc, A., Landre, M.F., Chastang, J.F., Niedhammer, I., Roquelaure, Y. 2001. Study Group on Repetitive Work. Upper-limb disorders in repetitive work. Scand. J. Work. Environ Health, 27: 268-278.

Lee, H.J. Delisa, J.A and Bach J.R.1999. The effect of temperature on antidromic median sensory 
conduction. Electromyogram Neurophysiology. 3: 33,125.

Letz, R., Cherniack, M.G., Gerr, F., Hershman, D., Pace, P. 1992. A cross-sectional epidemiological survey of shipyard workers exposed to hand-arm vibration. $\mathrm{Br}$. J. Ind. Med. 49(1): 53-62.

McCormack, R.R. Jr., Inman, R.D., Wells, A., Berntsen, C., Imbus, H.R.1990. Prevalence of tendinitis and related disorders of the upper extremity in a manufacturing workforce. $J$. Rheumatology. 17: 958-964.

Misra, U.K. and Kalita, J. 2008. Clinical Neurophysiology - Nerve conduction Electromyography and Evoked Potentials. Reed Elsevier India Pvt Ltd, New Delhi, India.

Morgenstern, H., Kelsh, M., Kraus, J., Margolis, W. 1991. A cross-sectional study of hand/wrist symptoms in female grocery checkers. Am. J. Ind. Med. 20(2): 209-218.

Musson, Y., Burdorf, A., van Drimmelen, D. 1989. Exposure to shock and vibration and symptoms in workers using impact power tools. Ann, Occup. Hyg. 33(1): 85-96.

Nathan, P.A., Keniston, R.C., Myers, L.D., Mekadows, K.D. 1992. Longitudinal study of median nerve sensory conduction in industry: relationship to age, gender, hand dominance, occupational hand use, and clinical diagnosis. J. Hand Surg. (Am) 17: 850-857.

National Institute for Occupational Health and Safety. 1997. Musculoskeletal Disorders and Workplace Factors. A Critical Review of Epidemiologic Evidence for Work-Related Musculoskeletal Disorders of the Neck, Upper Extremity, and Low Back (US Department of Health and Human Sciences/NIOSH, Cincinnati, OH) Publication no. 97-141.

Nilsson, T., Burström, L., Hagberg, M. 1989. Risk assessment of vibration exposure and white fingers among platers. Int. Arch. Occup. Environ. Health. 61(7):473-481.

Norris, A.H, Shock, N.W. and Wagman, I. H. 1953. Age changes in the maximum conduction velocity of motor fibers of human nerves. $J$. Applied Physiology, 5:,598.

Nordstrom, D.L., Vierkant, R.A., Layde, P.M., Smith, M.J. 1998. Comparison of self-reported and expert-observed physical activities at work in a general population. Am. J. Ind. Med. 34: 29-35.

Osorio, A.M., Ames, R.G., Jones, J., Castorina, J., Rempel, D., Estrin, W., 1994. Carpal tunnel syndrome among grocery store workers. Am. J. Ind. Med. 25(2): 229-245.

Palmer, K.T., Harris, E.C., Coggon, D. 2007. Carpal tunnel syndrome and its relation to occupation: a systematic literature review. Occup. Med. (Lond). 57(1): 57-66.

Roquelaure, Y., Mechali, S., Dano, C., Fanello, S., Benetti, F., Bureau, D., Mariel, J., Martin, Y.H., Derriennic, F., Penneau-Fontbonne, D. 1997. Occupational and personal risk factors for carpal tunnel syndrome in industrial workers. Scand. J. Work Environ. Health. 23: 364-369.

Roquelaure, Y., Mariel, J., Fanello, S., Boissière, J.C., Chiron, H., Dano, C., Bureau, D., Penneau-Fontbonne, D. 2002. Active epidemiological surveillance of musculoskeletal disorders in a shoe factory, Occup. Environ. Med. 59: 452-458

Rossignol, M., Patry, L., Sacks, S. 1998 Carpal tunnel syndrome: validation of an interview questionnaire on occupational exposure. Am. J. Ind. Med. 33(3): 224-31.

Ross, A., Leveritt, M. and Riek, S. 2001. Neural influences on sprint running training adaptations and acute responses. School of Human Movement Studies, University of Queensland, Brisbane, Australia.

Sandén, H., 2010. Nerve conduction in relation to vibration exposure - a non-positive cohort study. J. Occup. Med. Toxicol., 5: 21

Schottland, J.R., Kirschberg, G.J., Fillingim, R., Davis, V.P., Hogg, F. 1991. Median nerve latencies in poultry processing workers: an approach to resolving the role of industrial 'cumulative trauma' in the development of carpal tunnel syndrome. J. Occup. Med. 33: 627-631.

Silverstein, B.A., Fine, L.J., Armstrong, T.J. 1987. Occupational factors and carpal tunnel syndrome. Am. J. Ind. Med. 11: 343-358.

Spallek, M., Kuhn, W., Uibel, S., Mark, Anke van Quarcoo, D. $2010 \quad$ Work-related musculoskeletal disorders in the automotive industry due to repetitive work -implications for rehabilitation. J. Occup. Med. Toxicol., 5: 6.

Stetson, D.S., Albers, J.W. and Silverstein, B.A. 1992. Effects of age, sex and anthropometric factors on nerve conduction measures. Muscle and Nerve 15: 1095-1104.

Stetson, D.S., Silverstein, B.A., Keyserling, W.M., Wolfe, R.A., Albers, J.W. 1993. Median sensory distal amplitude and latency: 
Comparision between non exposed managerial/ Professional employees and industrial workers. Am. J. Ind. Med. 24(2): 175-89.

Stevens, J.C, Witt, J.C, Smith, B.E, and Weaver, A.L. 2001. The frequency of carpal tunnel syndrome in computer users at a medical facility. Neur. 56 (11): 1568-1570.

Sullivan, S.B. and Schmitz, T.J. 2001. Physical Rehabilitation Assessment and Treatment. Jaypee Brothers, New Delhi, India.

Tanaka, S., Wild,. D.K., Cameron, L.L., Freund, E. 1997. Association of occupational and nonoccupational risk factors with the prevalence of self-reported carpal tunnel syndrome in a national survey of the working population. Am. J. Ind. Med., 32: 550-556.

Viikari-Juntura, E., Silverstein, B. 1999. Role of physical load factors in carpal tunnel syndrome. Scand. J. Work. Environ. Health 25: $163-185$.

Werner, R.A., Franzblau, A. 1996. Hand dominance effect on median and ulnar sensory evoked amplitude and latency in asymptomatic workers. Arch. Phys. Med. Rehabil. 77(5): 473-6.

Wieslander, G., Norback, D., Gothe, C.J., Juhlin, L. 1989. Carpal tunnel syndrome (CTS) and exposure to vibration, repetitive wrist movements, and heavy manual work: a casereferent study. Br. J. Ind. Med. 46: 43-47. 